\title{
The Use of Geopolymers for the Disposal of Asbestos-containing Materials
}

\author{
Michat Łach $^{1, *}$, Katarzyna Lichocka ${ }^{1}$, Maria Hebdowska-Krupa ${ }^{1}$, Wei-Ting $\operatorname{Lin}^{2}$, and \\ Kinga Korniejenko ${ }^{1}$ \\ ${ }^{1}$ Cracow University of Technology, Faculty of Material Engineering and Physics, Institute of \\ Materials Engineering, Warszawska 24, 31-155 Cracow, Poland \\ ${ }^{2}$ National Ilan University, Department of Civil Engineering, Shennong Road, Yilan City, Yilan \\ County, 260 Taiwan
}

\begin{abstract}
Asbestos is widely known as a hazardous material and can contribute to many diseases. Its removal and neutralization are complicated, it requires proper preparation and the use of appropriate technology. Immobilization of asbestos materials in geopolymers seems to be one of the alternatives to its storage in landfills. However, this requires several studies confirming the possibility of asbestos immobilization in geopolymers. Also, asbestos dust contains silicon and aluminum, which may prove useful in the production of geopolymers. The paper presents research results regarding the possibility of using geopolymers based on fly ashes for neutralizing asbestos. An up-to-date literature review on the technology of managing asbestos-containing products is presented. As a result of the research, partial usefulness of geopolymerization technology for binding and neutralizing waste with asbestos was found. The research was carried out using waste asbestos-cement composites. Mixtures based on geopolymers were made in which ground asbestos material was introduced in an amount of 30,50 and $70 \%$ by weight. Compressive strength tests have shown that geopolymers with the addition of asbestos have compressive strength: over $34 \mathrm{MPa}$ for a composition containing $30 \%$ of asbestos material and about $14 \mathrm{MPa}$ for a composition containing $70 \%$ of asbestos material. SEM observations have shown that asbestos fibers do not dissolve in the geopolymer production process and they can still be a threat if the geopolymer matrix is damaged.
\end{abstract}

\section{Introduction}

The special mechanical and physicochemical properties mean that the global use of geopolymers is systematically increasing. Good mechanical strength as well as high resistance to high temperatures condition the use of geopolymers in many areas of the economy, especially in the construction sector. Geopolymers are considered ecological material because industrial waste is often used during production and the production process shows low carbon dioxide emissions [1-4]. Asbestos waste can be used for the production of geopolymer concrete, which must be properly prepared in advance [1].

\footnotetext{
*Corresponding author: michal.lach@pk.edu.pl
} 
As everyone knows, asbestos is a hazardous material and can contribute to many diseases and its removal is complicated and requires a proper preparation. The possibility of using waste aluminosilicate raw materials makes geopolymer technology seem to be one of the alternatives to asbestos storage in landfills. However, this requires several studies confirming the possibility of asbestos immobilization in geopolymers [1].

Appropriate use of asbestos waste is necessary from an economic and environmental point of view. Asbestos is banned in many countries, and world production is estimated at around 2,000 tons. Even though new recycling methods have been developed, asbestos management is still insufficient.

In the 20th century, the American industry used a whole range of asbestos products for production, construction and chemical refining. Asbestos products are still popular and used in developing countries such as Russia, India, China and Mexico [5].

Typical asbestos-containing products [5]:

- asbestos adhesives - roof sealants, insulating tapes, pipe lagging, kiln cement, adhesive for wall panels, floors and internal components

- asbestos duct joints - fabric joining HVAC system elements together

- asbestos felt - used on roofs, floors

- asbestos electrical components - wire insulation, cable braids, molded cement bases, ebonized panels, ignition protection paper

- fireproof asbestos - firefighting equipment, tar paper, paints, fireproof spraying

- asbestos gaskets - resistant to a higher temperature of the seal to connect valves, hoses and machine parts

- asbestos materials - used in tools, kitchen utensils, devices, vehicles, especially for brake pads

- asbestos products - protective clothing, fire blankets and upholstery

- asbestos vinyl products - floor tiles and panels, wallpaper

- asbestos insulation - insulation of blocks, pipes, loose and spray insulation and acoustic tiles

- asbestos sheets - corrugated sheets, flat cement sheets and drywall

A large number of scientific centers in Poland and the world are researching various methods of asbestos disposal. These methods rely on the destruction of the fibrous structure and then its transformation into a raw material that does not exhibit such characteristics [6].

Asbestos disposal methods include:

- Glazing and melting of fibers with fluxes or the use of plasma technology [6-8]: Glazing consists of combining asbestos waste into a homogeneous and stable glass. The process occurs at temperatures of $1200-1600{ }^{\circ} \mathrm{C}[6,8-11]$.

- Mechanochemical treatment using high-energy pouring equipment [6,8, 12-14]. Tests carried out on a laboratory scale $[6,12]$ showed that during mechanical processing in ball mills that operate at $250 \mathrm{rpm}$, for $12 \mathrm{~min}$. Pure asbestos samples and asbestos-cement composite panels were transformed into harmless end products. be used in mortars $[6,8$, 13].

- Dissolution of fibers in an acidic environment, incl. in sulfuric (VI) acid [6, 15-16] or organic acid (oxalic acid) [6, 17-18].

- MTT [19] (Microwave Thermal Treatment) technology - a state-of-the-art waste disposal option in energy reactors. At very high temperatures it is possible to dispose of a large range of hazardous waste. The costs of use are several times lower than currently known and used technologies and devices. The ATON HT company has developed "contactless" heating to optimal temperatures with a beam of microwave energy and the correct implementation of the process in a gas atmosphere. 
This article presents preliminary studies on the use of geopolymers for the utilization/solidification of asbestos waste.

\section{Materials and methods}

For the preparation of samples, composite materials with asbestos waste, geopolymers based on fly ash from the Skawina CHP Plant (oxide composition are presented in Table 1), activated with $8 \mathrm{M} \mathrm{NaOH}$ solution with aqueous sodium silicate (water glass), were used. The ratio of $\mathrm{NaOH}$ solution to water glass was 1:2. The samples were made in the shape of cubic cubes. Asbestos cement was used asbestos-cement crushed Eternit panels. Samples with $30 \%, 50 \%$ and $70 \%$ asbestos composite were prepared. Construction sand in a 1: 1 ratio (sand: fly ash) was also found in the geopolymer compositions.

For the preparation of geopolymer masses, technical sodium hydroxide was used in the form of flakes and an aqueous solution of sodium silicate R-145 with a molar module of 2.5 and a density of about $1.45 \mathrm{~g} / \mathrm{cm} 3$. The water that was added was "tap" water, no distilled water was used. The alkaline solution was prepared in this way, solid sodium hydroxide was poured with an aqueous solution of water and sodium silicate. The solution was mixed thoroughly and left until the concentrations equilibrated and a constant temperature was obtained. Solid components: fly ash and construction sand as well as introduced additives in the form of ground asbestos-cement composite were dry mixed until a homogeneous mixture was obtained, then the alkaline solution was added and thoroughly mixed. Mixing was carried out in a laboratory mixer for 15 minutes. After obtaining a homogeneous mass with a dense plastic consistency, the materials were transferred to molds, which were then subjected to vibration on a vibrating table. Geopolymer concretes were annealed in a laboratory drier for 24 hours at $75^{\circ} \mathrm{C}$ at atmospheric pressure. After 24 hours, the samples were removed from the molds.

Asbestos-concrete composites of the Eternit type were crushed by crushing in a jaw crusher and then milling in a roller mill.

Table 1. Oxide composition of fly ash.

\begin{tabular}{|l|l|l|l|l|l|l|l|l|}
\hline \multirow{2}{*}{} & \multicolumn{6}{l|}{ Oxide composition (wt.\%) } \\
\cline { 2 - 9 } & $\mathrm{SiO}_{2}$ & $\mathrm{TiO}_{2}$ & $\mathrm{Fe}_{2} \mathrm{O}_{3}$ & $\mathrm{Al}_{2} \mathrm{O}_{3}$ & $\mathrm{CaO}$ & $\mathrm{MgO}$ & $\mathrm{K}_{2} \mathrm{O}$ & $\mathrm{Na}_{2} \mathrm{O}$ \\
\hline Fly ash & 55.9 & 1.09 & 5.92 & 23.49 & 2.72 & 2.61 & 3.55 & 0.59 \\
\hline
\end{tabular}

Compressive strength tests were carried out by EN 12390-3 [20], using a Matest $3000 \mathrm{kN}$ compression press. These tests were carried out on 50 × 50 × $50 \mathrm{~mm}$ cubic samples conditioned at room temperature for 14 days. Three replicates were performed for each type of sample.

Geopolymer absorbability tests were carried out by PN-EN 206 [21]. The tests were carried out on 50x50x50 mm samples. The samples were stored under the same conditions as those for the compressive strength tests. The tests were carried out 14 days after the samples were demoulded.

\section{Results}

Figure 1 below shows the surface appearance of geopolymer composites with the addition of ground asbestos waste. Even despite the high proportion of asbestos waste, no fiber asbestos was observed on the surface of the samples. The surfaces of the samples, apart from traces of mold mapping and traces of air bubbles, remained smooth. 

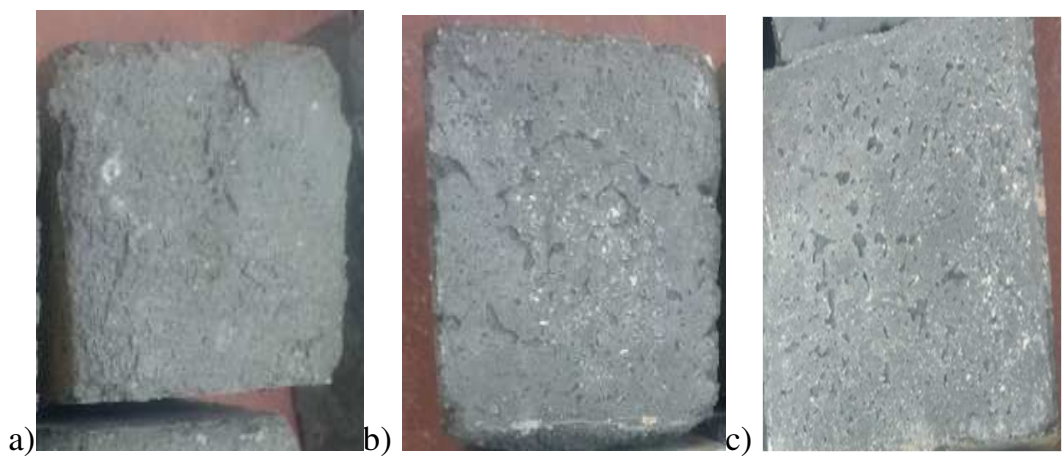

Fig. 1. The appearance of example geopolymer composites containing asbestos waste: a) $30 \%$ by weight, b) $50 \%$ by weight, c) $70 \%$ by weight.

Table 2 below presents the results of testing the compressive strength and absorbability of geopolymers containing asbestos waste. Samples containing no waste and containing $30 \%$ of asbestos waste were characterized by the highest compressive strength. Their compressive strength was about 34-35 MPa. For samples containing 50\% of asbestos waste, the compressive strength was $14.3 \mathrm{MPa}$. For $70 \%$ asbestos, the compressive strength was only 13.8 MPa. Sambas with $30 \%$ asbestos and samples without asbestos waste were characterized by the highest absorbability. Their absorbability was about $10 \%$. The absorbability of the samples for the $50 \%$ asbestos addition was $9.88 \%$. The lowest absorbability was found in samples with $70 \%$ asbestos, and absorbability was $7.085 \%$. The results presented in Table 2 are also presented graphically in the graph (figure 1).

Table 2. Results of testing the compressive strength and absorbability of geopolymers containing asbestos waste.

\begin{tabular}{|c|c|c|c|}
\hline Sample no. & Asbestos waste content & Compressive strength & Water absorption \\
\hline KL0 & $0 \%$ & $35.7 \pm 1.35 \mathrm{MPa}$ & $10.05 \%$ \\
\hline KL1 & $30 \%$ & $34.8 \pm 2.22 \mathrm{MPa}$ & $10.07 \%$ \\
\hline KL2 & $50 \%$ & $14.3 \pm 1.98 \mathrm{MPa}$ & $9.88 \%$ \\
\hline KL3 & $70 \%$ & $13.8 \pm 2.42 \mathrm{MPa}$ & $7.085 \%$ \\
\hline
\end{tabular}




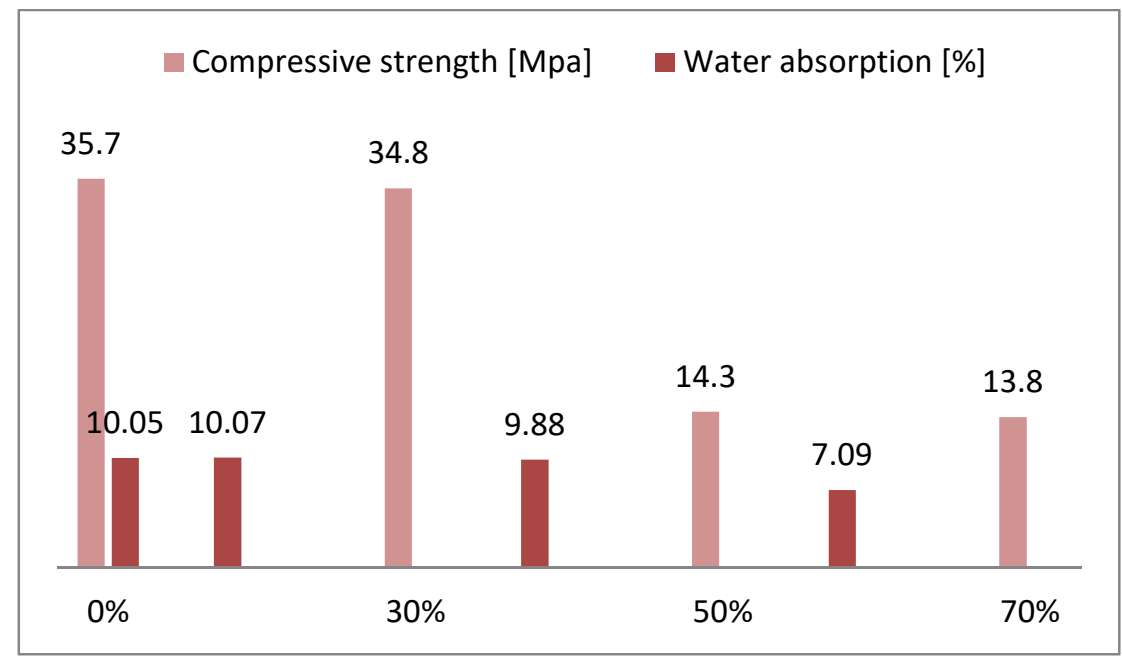

Fig. 2. Presentation of the results of compressive strength and absorbability for geopolymer composites with asbestos waste.

Observations of the structure of geopolymers containing asbestos waste, using a scanning electron microscope, made it possible to visualize asbestos fibers. Figures 2 and 3 show the morphology of the geopolymer structure containing $30 \%$ asbestos waste (figure 2) and 50\% (figure 3). Asbestos fibers are very clearly visible, which did not dissolve during the alkaline activation of raw materials in the production of geopolymers.

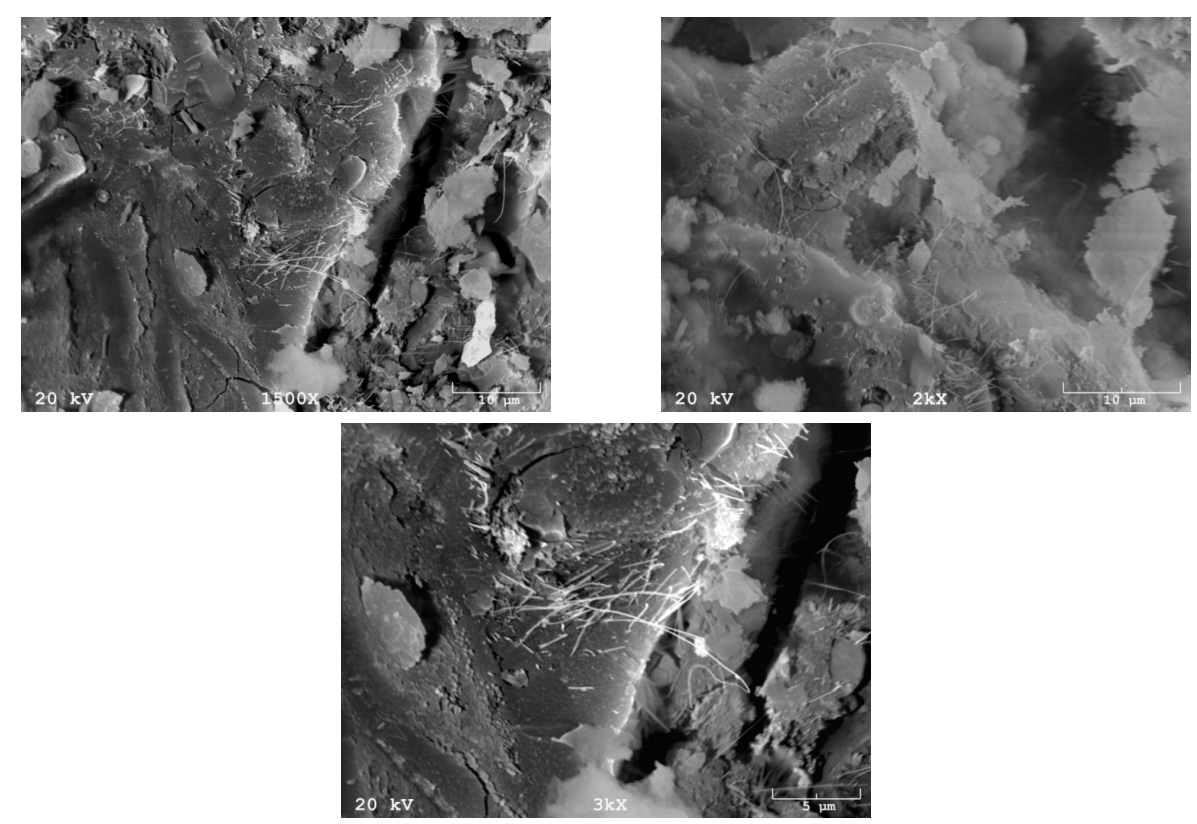

Fig. 3. SEM micrograph of samples containing $30 \%$ asbestos addition. 

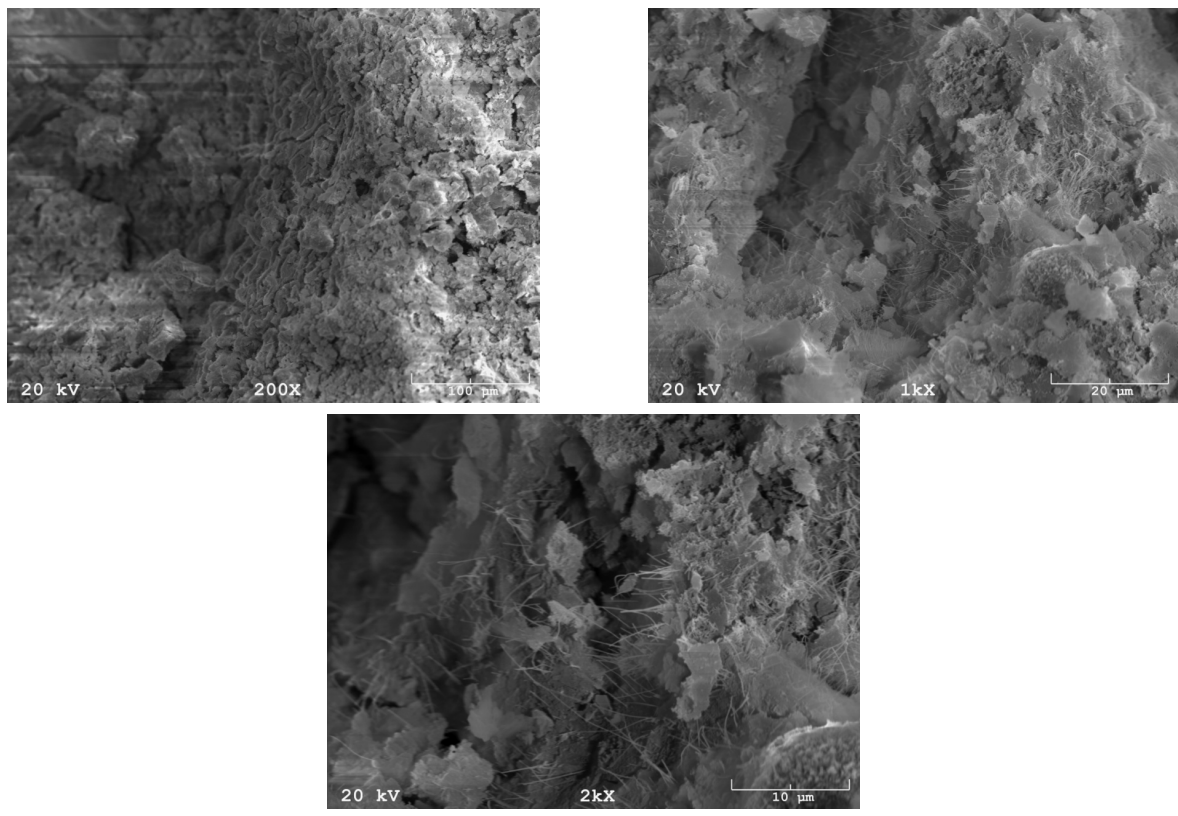

Fig. 4. SEM micrograph of samples containing $50 \%$ asbestos addition.

The conducted tests only to a limited extent confirmed the ability to immobilize asbestos fibers in geopolymers. The authors of the article expected better results in terms of the degradation of these fibers in an alkaline environment. The results obtained and the visible unreacted fibers observed in the SEM study suggest that in the event of damage/degradation of such geopolymer composites, asbestos fibers may still leak into the environment and pose a threat to human health. It is also worth emphasizing that the utilization of large amounts of asbestos waste in geopolymers, over $30 \mathrm{wt}$. leads to a significant reduction in the mechanical properties of such composites.

\section{Summary}

The research allowed to formulate the following conclusions:

1. Samples with $30 \%$ by weight asbestos material have the highest compressive strength, it is similar to the compressive strength of geopolymers without the addition of asbestos. The introduction of asbestos material in larger quantities at the level of 50\% and $70 \%$ led to a decrease in geopolymer compressive strength.

2. Materials with $30 \%$ asbestos were characterized by the highest water absorption, while asbestos in the amounts of 50 and $70 \%$ had lower water absorption.

3. SEM scanning microscope observations have shown that asbestos fibers do not break up in the process of alkaline activation and geopolymer formation and can still be a threat if the geopolymer matrix is damaged.

Geopolymer materials can be an alternative to the disposal of asbestos-containing materials, but some additional tests are needed to confirm the usefulness and effectiveness of this method in the disposal of asbestos-containing materials. As a result of the research, only partial use of geopolymerization technology for binding and neutralization of asbestos waste was found. To improve efficiency, it would be necessary to carry out research related to the optimization of geopolymerization recipes or to carry out tests on the utilization of asbestos waste in an acidic environment and to produce geopolymers in acid activation processes. 
This work has been financed by Polish National Agency for Academic Exchange under the International Academic Partnership Programme within the framework of the grant: E-mobility and sustainable materials and technologies EMMAT(PPI/APM/2018/1/00027).

\section{References}

1. M. Wójcik, RUTMech XXXV 90, 245-253, (2018)

2. M. Łach, D. Mierzwiński, K. Korniejenko, J. Mikuła, M. Hebda, J. Air Waste Manag. Assoc. 68, 1190-1197 (2018)

3. J. Mikuła, Rozwiazania proekologiczne $w$ zakresie produkcji : Nowoczesne materiały kompozytowe przyjazne środowisku, (Wydawnictwo Politechniki Krakowskiej, Kraków, 2014)

4. L. Provis, J. S. J. Van Deventer, Geopolymers: structure, processing, properties and industrial applications, (Woodhead Publishing, Cambridge, 2009)

5. https://www.asbestos.com/products/ (December, 2019)

6. J. Pyssa, Odpady przemysłowe i niebezpieczne $w$ gospodarce obiegu zamkniętego, (Wydawnictwo AGH, Kraków, 2019)

7. A. Viani, A.F. Gualteri, S. Pollastri, C. Rinaudo, A. Croce, G. Urso, J. Hazard. Mater. 248-249, 69-80 (2013)

8. D. Spasiano, F. Pirozii, J. Environ. Manage. 204, 82-91 (2017)

9. F. Dellisanti, P. L. Rossi, G. Valdare, Int. J. Miner. Process. 91, 61-67 (2009)

10. X. Tu, L. Yu, J. Yan, K. Cen, B. G. Chéron, IEEE Plasma Sci. 38, 3319-3325 (2010)

11. E. Bernardo, L. Esposito, E. Rambaldi, A. Tucci, Adv. Appl. Ceram. 110, 346-352 (2011)

12. P. Plescia, D. Gizzi, S. Benedetti, L. Camilucci, C. Fanizza, P. De Simone, F. Paglietti, Waste Manage. 23, 209-218 (2003)

13. F. Colangelo, R. Cioffi, M. Lavorgna, L. Verdolotti, L. De Stefano, J. Hazard. Mater. 195, 391-397 (2011)

14. A. Bloise, A. Gualteri, M. Catalano, Minerals 8, 135-152 (2018)

15. M. Rozalen, F. J. Huertas, Chem. Geol. 352, 134-142 (2013)

16. S. N. Nam, S. Jeong, H. Lim, J. Hazard. Mater. 265, 151-157 (2014)

17. A. Valouma, A. Verganelaki, P. Maravelaki-Kalaitzaki, E. Gidarakos, J. Hazard. Mater. 305, 164-170 (2016)

18. A. Valouma, A.Verganelaki, I. Tetoros, P. Maravelaki-Kalaitzaki, E. Gidarakos, J. Hazard. Mater. 336, 93-100 (2017)

19. http://www.eko-proj-edu.pl/inzynieria.html (June 2020)

20. EN 12390-3 (2019)

21. EN 206+A1 (2016) 